\title{
Development of Hospice and Palliative Care Services in Germany. A Case Study
}

\author{
Michaela Thönnes ${ }^{1 *}$, Nina R. Jakoby ${ }^{1}$ \\ ${ }^{1}$ Department of Sociology, University of Zurich, Andreasstr. 158050 Zurich, Switzerland
}

Received: November 14, 2016; Accepted: November 26, 2016; Published: December 04, 2016

*Corresponding author: Michaela Thönnes, Department of Sociology, University of Zurich, Andreasstr. 158050 Zurich, Switzerland, phone:+41 (0)44635 2370;Email: thoennes@soziologie.uzh.ch

\begin{abstract}
The paper shows how, over a period from the 1980s until today, individually experienced pressure to act, inspiration, and commitment has led to collective solutions for improving care for the dying. The German case study further exemplifies how creative solutions can be devised to empower society and its members. We found a remarkable model of providing extensive care services to the dying and their relatives based on voluntary involvement in a medium-sized city in Germany. The city's hospice and palliative care services were investigated based on a qualitative network analysis.
\end{abstract}

Keywords: Palliative care; Hospice; Dying; Places of death; Volunteers; Germany; Case study

\section{Introduction}

The sophisticated welfare systems throughout the European Union extend legally constituted rights of social security to all. Since the early 1980s cutbacks in western European health and welfare systems has fuelled concern that the dying, who already face a heavy burden, for structural reasons will have to shoulder an even greater one. Still today, there is a lasting fear throughout Europe of institutionalized dying in an anonymous hospital setting. Demographic change, which is a characteristic trend observed in all modern EU countries, has heightened such concerns. The hospital, nursing home and the family are facing challenges with regard to the care of the dying. In brief, the hospital can best be characterized by the view to see death as a failure of medicine. This discourse is manifested through a) increasing technological interventions for a prolongation of life [1] and b) a lack of communication between professionals and the dying [2]. Furthermore, caring for the dying in hospitals occurs in a paradoxically depressing atmosphere of rising costs in the German healthcare system while national strategies and laws installed to lower expenses for healthcare obviously remain ineffective [3]. There are a number of reasons for admitting terminally ill people. Patients are assessed by those close to them

${ }^{1} \mathrm{~A}$ short version of the paper was presented at the 15 th International Research Conference "Dilemmas for Human Services", Theme: Hard Times for Human Services, London (UK), 2011. or by themselves as not being terminally ill and are to receive remedial treatment, despite the pre-final stage of their condition. On the other hand, symptoms during the final stage of life at home can be so stressful and impossible to manage any more that the only solution is deemed to be pain management or treatment of the symptoms in the hospital. In both cases, admission to a hospital always culminates in the use of services and resources for the terminally ill that are largely therapeutically oriented, despite the explicit aim of providing palliative medicine.

Dying in a hospital will always involve more costs than would have been the case in any other institutional context. Because of the therapeutic possibilities administered, we can even expect the process of dying to be lengthened or rendered more difficult. The criticism refers explicitly to overtreatment and aggressive therapy involving invasive procedures, operations and costly measures at the end of life [4,5]. A recent metaanalysis of international studies found that, on average, onethird of patients with advanced irreversible diseases received non-beneficial treatments in hospitals near the end of their lives [6]. This included these patients being subject to chemotherapy, radiotherapy, blood transfusion, scans, resuscitation or feeding tubes during the last few weeks of their lives. The main reasons for this futile treatment were strong orientation of medical staff towards curative treatment as well as their discomfort and inexperience with death and dying, the requests of family or the patients themselves, and institutional factors such as a high degree of specialisation and organisational barriers [7].

Nursing homes are often confronted with a lack of palliative knowledge, education and medical facilities to take care of dying residents. Moreover, increasing financial pressure from the primacy of economic principles and the resulting competitive situation of homes for the elderly implies that dying cannot be managed adequately. In many cases, terminally ill residents are moved from the nursing home to hospitals in the expectation that medical technology still can save them. In addition, demographic transitions, the increasing number of women in labour force and geographical mobility as features of modern society influence the availability of informal care of family members [1,2]. Further, families taking care of the dying at home are faced with a lack 
of ambulant home care services. Basic requirements for dying at home are relatives that are able to cope with the situation both physically and emotionally ("family care giver burden"), the availability of ambulatory palliative care, and suitable conditions in terms of space and necessary technical equipment for care $[8,9,10]$. In contrast to the hospital, the home as the place of dying holds the promise of being able to manage the dying situation and maintaining control over the medical treatment [2].

The review of literature reveals that the large majority of people asked about their preferences wish to die at home and not in an institution. Studies show that this holds true for 50 to 90 per cent of those asked about their preferences $[10,11]$. Both the dying and their relatives associate the idea of a "good death" with it happening at home $[12,13]$. Images of a good death also include aspects such as autonomy and respect, adequate pain therapy and management, and being informed about the medical prognosis [12]. These values are diametrically opposed to the number of people that actually die at home, the share of which generally hovers around 20 to 30 per cent in a cross-national comparison [14,15]. Exceptions are, for instance, the German state of Rhineland-Palatinate at 37.3 per cent in 1995 [16]. In Brussels (Belgium), on the other hand, the rate of those dying in their private home is particularly low at 15.1 percent [17].

The term institutionalization carries the negative connotation of being the typical form of dying in modern service societies. It evokes images of loneliness, isolation and helplessness [18]. In this largely unexplored area, however, a normative evaluation of places of dying as "good" or "bad" is not possible as long as we lack properly defined criteria and empirical findings. The fairly high and, over many years, constant percentage of persons dying at home ranging between 20 to 30 per cent additionally casts doubt on the classic institutionalization of dying thesis [10]. Thus, dying in institutions cannot simply be deemed the "normal case" in modern society [19]. Moreover, there are signs for a shift from hospitals to retirement homes. This fact may also involve a shift in the experience of dying and possibly in the quality of dying since for many people residing in retirement or nursing homes, their retirement or nursing home actually becomes their "home".

Of the 827,155 deceased in Germany in 2008, 12.5 per cent were in hospice or palliative care. From 1996 till 2008 the share of ambulatory hospice services in Germany has steadily increased approximately fourfold. The number of in-patient hospice wards doubled between 2000 and 2001 from 62 to 123 units. Although the development slowed down in the following seven years, the number of hospice units increasing up to 163 until 2008, the rate of increase was similar to the early years of establishing hospice facilities when 31 in-patient units had been created from 1996 to 2000 [20]. In Germany the first palliative unit was opened in 1983 at Cologne University Hospital and the first hospice was founded in 1986 by Pastor Otto Türks in Aachen. Even now, country-wide provision of ambulatory care for the dying has not been achieved; it is still very much a matter of home care for the sick or the elderly. As a rule, this is carried out by family members, family practitioners and general nursing services provided on a voluntary basis. This general care is for the most part limited to maintaining the physical functions by performing or providing assistance with personal hygiene, dressing or administering medication and often does not cover psychosocial support, information for the family members or social networking of any kind. It neither ensures 24-hour pain management nor does it provide the medical services necessitated during the process of dying. All palliative or hospice services in Germany still depend on good will, voluntary commitment and informal know-how, regionally broken down into hospice and palliative facilities. The figures published by the German Hospice and Palliative Association (Deutscher Hospizund PalliativVerband) on their homepage and the database "Wegweiser Hospiz- und Palliativmedizin" (Guide to Hospice and Palliative Medicine) point to a rise in the number of ambulatory hospice and palliative services from 451 in 1996 to about 1500 in the year 2016 (http://www.dhpv.de/service_zahlen-fakten.html, accessed on 11/27/2016).

In the case of Germany, the efforts of the federal government in the form of amendments to social legislation and the creation of the social code paragraphs $\S \S 37 \mathrm{~b}$ SGB V and 132d SGB V ("Special Ambulatory Palliative Care") in 2007 have up to now failed to ensure any significant expansion of palliative care services for the dying (http://www.sozialgesetzbuch-sgb.de/ sgbv/37b.html and http://www.sozialgesetzbuch-sgb.de/ sgbv/132d.html, accessed on 11/27/2016). The aforementioned paragraphs, which also define the precise allocation of services through Special Ambulatory Palliative Care (SAPC) in the form of numbers awarded to the respective operational sites, render the funding of specially trained and properly compiled care giving and medical personnel possible in a palliative team. Yet such funding has in fact only been regulated by contract between the local health insurance body and the applicant nursing service in 295 cases throughout the country up until 27 July 2016, according to information received from the Federal Union of Panel Doctors (http://www.kbv.de/html/palliativversorgung.php, accessed on 11/27/2016).

Nevertheless, contemporary society is marked by the insufficient availability of hospice or palliative care services for the dying in many parts of Europe, both of the in-patient and especially of the ambulatory kind. This affects the rural population more strongly than the residents of urban agglomerations.

\section{A German Case Study: The City of Aachen}

In spite of the widespread social and individual helplessness in dealing with the dying and the lack of prospects for future betterment, we found a remarkable model of providing extensive care services to the dying and their relatives based on voluntary involvement in a medium-sized city in Germany. The following general research question guided the analysis: How can the development of hospice and palliative care services be described and explained? The Aachen network has assumed a pioneering role in developing ambulatory hospice and palliative medicine in Germany. This network, built on voluntary commitment that caters to a particularly difficult subject of social relevance, 
namely the desire for humane death in a personal and private context within the bounds of a high-tech and medicating society has continued to grow and now, after some 30 years, displays stable forms of institutionalization. In the summer of 2010 an independent analysis was carried out of publications in the print and digital media specifically focusing on network structure, flows of development, developmental forecasts and turning points, likewise on communication flows and points of intersection, in order to then conduct interviews with specific experts within the network. Narrative and expert interviews were conducted with Maggie Hunt and the coordinator of Aachen Hospice Service (all names have been changed, M.T., N.J.). In sum, the qualitative network analysis provided information on the network structures and its actors by collecting network information using media coverage and digital information, such as the homepages of various institutions of hospice and palliative network in Aachen. Finally, a visual representation of the network demonstrated how the various institutions and the relationships between the network members developed over time.

In the winter of 2009, the so-called Federal Cross of Merit was awarded to Maggie Hunt on the grounds of her successful and pioneering work as a volunteer in hospice care in the city of Aachen. The foundation of one of the two first homecare hospice groups in Germany in the year 1999 and her commitment still today as volunteer can be traced back to her painful experience of taking care of her thirty-one year old son Peter who died of cancer in 1996. The initial trigger for her commitment to palliative care in Aachen can best be explained by the following quotation:

"The reason was that Peter said, 'Well, I have you. But what do the ones do who have to go through this alone?"'(Maggie Hunt, 09/29/2009, translated into English)

After experiencing a devastating lack of support from general practitioners and a lack of adequate pain management for her son that could be attributed to insufficient experience and understanding on the part of medical professionals in dealing with a patient dying at home, she became alerted to the basic need for improvement in the homecare of the terminally ill. The following quotation from Maggie Hunt illustrates the situation prior to the systematic development of ambulatory palliative care in Aachen:

"But at the time, "Homecare" did not exist. We had no competent physicians; they were all just trying it out a bit, to provide pain therapy. Peter was in such pain! Indescribable! Today with Homecare he would have been incorporated into palliative care day and night. How clueless we were then during the nights!" (Maggie Hunt, 09/29/2009, translated into English).

The deficit in ambulatory care for the dying mentioned here in an interview was typical in 1995 for Germany and, bar a few exceptions, still applies today. Maggie Hunt started up a number of different projects and local strategies and was the main initiator behind the growing network for home-based hospice care in Aachen. For example, she built up schemes for the education and training of those involved in hospice and palliative care that now embody an essential part of the current quality certificate of the
Aachener Hospizstiftung (Aachen Hospice Foundation). Beside her function in coordinating training and education in palliative care, for the past fifteen years Maggie Hunt has also been responsible for organising the volunteers engaged in homecare hospice work in Aachen.

Even before Maggie Hunt became involved, there were in fact already a few pilot projects in Aachen. In this respect, Aachen provided a structural opportunity for developing further palliative care initiatives. It was here where in 1986 the first inpatient hospice in Germany was established. Moreover, in 1995 a small private group of people who were dissatisfied with the situation and the attitudes towards the terminally ill within the German healthcare system had the chance of discussing their concerns and outlooks in public in an institutionalized setting with professionals, thereby putting forward possible solutions for improving terminal care. These public events became known as Hospizgespräche Aachen (The Aachen Hospice Dialogue). They still constitute an important part of the palliative network in Aachen and reflect the impact of public involvement and awareness, voluntary organisations and people's empowerment for social change. At an average of five events each year, resources are consolidated, information and ideas exchanged and the idea of the hospice developed further. Derived from the idea of continuing education and networks at regional level, the Aachen Hospice Dialogue has become one of the most important professional symposia in the country for hospice and palliative networking and continuing education. Out of the 23 different institutions at the outset, the number of facilities, services and professionals invited to the symposium rose in 2010 to 350 , all of which focus on continuing education and networking five times a year at regional and national congresses. A permanent feature of the Aachen Hospice Dialogue is that it "tours" through the region. Each regional or national congress is hosted by a different institution, which sometimes also prepares the actual contents of the congress. A significant outcome of this tradition is that the network participants acquire a broad insight into the diversity of what is on offer in the region as well as the various competencies. At the same time, a solid basis is created for furthering and administering the network platform. Against this backdrop, it was possible to set up the registered palliative network for the region of Aachen (Verein Palliatives Network für die Region Aachen e.V) in 2008.

The members of this registered association come from all walks of life that are central to hospice and palliative care: palliative units, hospice homes, ambulatory hospice services, Home Care Aachen e.V., family practitioners, medical consultants, A\&E physicians, homes for the elderly, hospitals, spiritual counselors, grief counselors, physiotherapists, pharmacies, healthcare supplies stores, hospice service offices, undertakers, health insurance companies, local administrations etc. (source: http://www.servicestelle-hospizarbeit.de/netzwerk.php, accessed on 11/28/2016).

The most innovative element towards the end of the 1990 s is attributable to the activities of volunteers in bringing together the various different initiatives to establish one single institution, 
at the same time developing better care for those who are dying at home. From 1999 until 2001, three streams - i.e. a) the Aachen Hospice Dialogue, b) two volunteer homecare hospice groups and c) the hospice Haus Hörn and the inpatient palliative unit in the municipality of Würselen (eight kilometres from Aachen) culminated into yet another important development in the current Hospice and Palliative Network. In 2001, the city of Aachen set up the Servicestelle Hospiz Aachen (Aachen Hospice Service). Initially addressing twenty-three and now dealing with nearly two hundred hospice and palliative medical institutions, this central hospice service offers advanced training and continuing education for all medical professionals and caregivers engaged in the hospice and palliative field throughout Germany, Germanspeaking Europe and the Aachen region. Moreover, Aachen Hospice Service is responsible for public relations and acts in an advisory capacity for institutions and care team professionals and volunteers. The subject of "dying" has actually long been accepted as one of paramount importance given the foundation in 2001 of the palliative group Home Care and then in 2003 the chair for palliative medicine at RWTH Aachen University (Table 1).

Most interestingly, Aachen proved to be rather imaginative in bringing the subject of hospice and palliative work alongside an awareness of death closer to broad sectors of society. The main cultural event in the Rhineland is the carnival celebration and during the winter of 2005/2006, events kicked off on 11 November 2005 under the motto of "Carnival and Death" [21]. In fact, it was the Aachen Hospice Service together with the leading local carnival association in charge of nominating the so-called "Carnival prince" that were responsible for this project, which aimed to trigger greater public awareness of the subject. One of the members of this local carnival association is the then acting Minister of Health, a woman who grew up in Aachen and still lives there. The reform of the Healthcare System in Germany in February 2007 featured two important paragraphs: §37b SGBV and $\S 132 \mathrm{~d}$ SGBV. These paragraphs provided for the financing of Special Home-Based Palliative Care (SAPC) by the healthcare system, a prospect unheard of previously, and were undoubtedly the outcome of the influence exerted by the Special Palliative Care System in the United Kingdom and the implementation of the policies of the Bologna Process, on the one hand, and of the experience already gained from Home Care and the hospice and palliative network (Aachen Hospice Service) on the other.

Table 1: Internet Sources of Palliative Care in Aachen (accessed on 11/28/2016)

Aachener

Hospizgespräche http://www.servicestellehospizarbeit.de/

[The Aachen Hospice hospizgespraeche.php

Dialogue]

Servicestelle Hospiz

Aachen

[Aachen Hospice http://www.servicestelle-hospizarbeit.de/

Service] netzwerk.php

Home Care Aachen http://www.homecare-aachen.de/

Bildungswerk Aachen

[Aachen Education Institute]

http://www.bildungswerkaachen.de/index.php/ bildung/kursliste/4/22/72

\section{Conclusion}

The paper shows how, over a period from the 1980s until today, individually experienced pressure to act, inspiration, and individual commitment has led to collective solutions for improving care for the dying. The city of Aachen further exemplifies how creative solutions can be devised to empower society and its members. In order to explain the reasons why hospice and palliative care services were developed here, leading to improved services for the dying and their relatives, the situation can be described with regard to the following aspects: commitment of private individuals, group initiatives, initiatives by professionals, public demand and public perception as well as political and legal effects and consequences. Over the past years, the Aachen Hospice Service has grown which on the one hand manages resources, takes the development of hospice initiatives farther, provides a hospice telephone hotline and embodies the administrative centre for implementation, qualification, communication and coaching for the hospice and palliative network process. On the other hand, the organisation counts some eighty volunteers who engage throughout different institutions and act as case managers and pilots in the healthcare system. Besides their genuinely practical and fundamental function as hospice network care managers, the volunteers also bridge the gap in communication between the healthcare system itself, the family and the terminally ill. These volunteers and those who provide psychological support to the terminally ill, mirror the two major elements of the difference between the outpatient palliative care system and the general outpatient healthcare system. Given this setting and because of the fact that they also open the door to other social contexts, volunteers make up the backbone of hospice and palliative work.

The following looks at the specific constellations that have furthered the development of palliative care in Aachen and shows why the situation in Aachen differs from that of other towns. Given the pioneer role of Aachen in this respect and the benchmark thus set in the field of ambulant hospice and palliative care providers, the medical, structural and contractual network competencies necessary to qualify as a contract partner for the health insurance scheme have already been in existence since 2002 and do not first have to be procured as is the case in other regions of Germany. The network as a whole is structured in a way that not only reflects the bond with the educational institution Bildungswerk Aachen (Aachen Education Institute) and the neutrality towards the confessional beliefs of the dying and those close to them but also clearly demonstrates an obvious disregard for any financial interests of its own as service provider. Maggie Hunt and the coordinator of Aachen Hospice Service underline the secular and voluntary credo of institutionalization by creating of a coordinator position in 1999. On the one hand, this step helps those who are dying and the people close to them to overcome their inhibition in calling for assistance or even becoming actively committed themselves to the network. On the other hand, the network plays a considerably greater part in transporting knowledge about people who are terminally ill into society. Setting up an association also means 
that all those taking part are prepared to submit to a joint board and on an equal footing to delegate competencies. Not only this, reports are a mandatory requirement, resulting in transparency, a factor that deters other institutions from networking. Likewise of particular note is the high degree of cooperation available within the network alongside the clear definition and contractual demarcation of the various competencies. No member of the network takes on a field of assignment of another. The hospice group, for example, does not intervene in nursing activities. At the same time, membership to the network is subject to high quality standards that have to be met. The network not only seeks to protect the dying from incompetence but also to prevent volunteers or interested members from wrongly assessing their own abilities, yet another factor that lends greater stability to the network. Finally, mention should be made of the open mind-set of the people of Aachen and of the Aachen Carnival Club, which staged new and exceptional ideas on the subject with its carnival contribution entitled "Carnival and Death" [21].

\section{References}

1. Howarth G. Death \& Dying. A Sociological Introduction. Cambridge: Polity Press; 2007.

2. Glaser BG, Strauss AL. Time for Dying. New Brunswick/London: Aldine Transaction; 2007.

3. Statistical Yearbook 2010 for the Federal Republic of Germany including »International tables«. WOiesbaden: Federal Statistical Office; 2010.

4. Jox RJ, Schaider A, Marckmann G, Borasio GD. Medical futility at the end of life: the perspectives of intensive care and palliative care clinicians. Journal of Medical Ethics. 2012;38(9):540-545. doi:10.1136/ medethics-2011-100479.

5. Thöns M. Patient ohne Verfügung: Das Geschäft mit dem Lebensende. München/Berlin: Piper; 2016.

6. Cardona-Morrell M, Kim JCH, Turner RM, Anstey M, Mitchell IA, Hillman K. Non-beneficial treatments in hospital at the end of life: a systematic review on extent of the problem. International Journal for Quality in Health Care. 2016. doi:10.1093/intqhc/mzw060 456-469, $1-14$.

7. Willmott L, White B, Gallois C, Parker M, Graves N, Winch S, Callaway LK, Shepherd N, Close E. Reasons doctors provide futile treatment at the end of life: a qualitative study. 2016;42(8): 496-503.doi: http:// dx.doi.org/10.1136/medethics-2016-103370.
8. Bowling A. The hospitalisation of death: Should more people die at home? Journal of Medical Ethics. 1983;9:158-161.

9. Bell C, Somogyi-Zalud E, Masaki KH. Factors associated with congruence between preferred and actual place of death. Journal of Pain and Symptom Management. 2010;39(3):591-604. doi:10.1016/j. jpainsymman.2009.07.007.

10. Thönnes M, Jakoby N. Where people die. A critical review. Medical Sociology online. 2013;7(1):8-19.

11. Rebscher H. editor. Pflegereport 2016. Palliativversorgung: Wunsch, Wirklichkeit und Perspektiven. Heidelberg: medhochzwei Verlag.

12. Gardner DS, Kramer BJ. End-of-Life concerns and care preferences: Congruence among terminally ill elders and their family caregivers. Omega: Journal of Death and Dying. 2009;60(3):273-297.

13.Vig EK, Davenport NA, Pearlman RA. Good deaths, bad deaths, and preferences for the end of life: A qualitative study of geriatric outpatients. American Geriatrics Society. 2002;50(9):1541-1548.

14. National End of Life Care Intelligence Network 2010: Variations in Place of Death in England. Inequalities or appropriate consequences of age, gender and cause of death. Available at: http://www. endoflifecare-intelligence.org.uk/resources/publications/variations_ in_place_of_death, 11/28/2016.

15. Mikulasek, A. Kap. 4 Gestorbene - Deaths. In: Statistik Austria (ed.): Demographisches Jahrbuch 2010. Wien: Verlag Österreich $\mathrm{GmbH}_{\text {; }}$ 2011.

16. Ochsmann R, Feith G, Klein T, Seibert A, Slangen K. Sterbeorte in Rheinland-Pfalz: Zur Demographie des Todes. Beiträge zur Thanatologie. 1997;8:1-49.

17. Houttekier D, Cohen J, Bilsen J, Deboosere P, Verduyckt P, Deliens, L. Determinants of the place of death in the Brussels metropolitan region. Journal of Pain \& Symptom Management. 2009;37(6):9961005.

18. Elias, N. The loneliness of the dying. New York/London: Continuum;2001.

19. Feldmann, K. Tod und Gesellschaft. Sozialwissenschaftliche Thanatologie im Überblick. Wiesbaden:VS-Verlag; 2004.

20.HPCV-Studie: Hospizliche Begleitung und Palliative-CareVersorgung in Deutschland, 2008. Available at: https://www. stiftung-patientenschutz.de/uploads/files/pdf/publikationen/HPCVStudie_2010.pdf. 11/28/2016.

21. Tod und Karneval ("Carnival and Death"). Available at: http:// www.servicestelle-hospizarbeit.de/pdf/TodundKarneval15.pdf. $11 / 27 / 2016$ 